\title{
Assessing the Vulnerability of Wastewater Facilities to Sea-Level Rise King County Wastewater Treatment Division
}

JOHN PHILLIPS ${ }^{1^{*}}$, CATHIE SCOTT $^{1}$, SHAUN O'NEIL ${ }^{1}$ Volume 3, Spring 2015

http://dx.doi.org/10.3998/mjs.12333712.0003.011

${ }^{1}$ King County Department of Natural Resources and Parks, Wastewater Treatment

Division, 201 S. Jackson St. KSC-NR-0503, Seattle, Washington, 98104

*Corresponding Author: John Phillips, john.phillips@kingcounty.gov

\section{ABSTRACT}

Sea-level rise poses a direct and measureable threat to low-lying infrastructure in tidally influenced areas. For the last half of the $20^{\text {th }}$ century, the mean sea level in Puget Sound has increased 4.24 inches. In the most likely sea-level rise scenario, it is predicted to rise an additional 6 inches by 2030 and 13 inches by 2100 as the result of climate change. Storm surges are expected to increase tide heights even more. King County's regional wastewater system serves 1.5 million people in the greater Seattle area. Salt water is entering the system during high tides. To determine the potential for greater amounts of saltwater inflow, the county assessed the vulnerability of its facilities using combinations of predicted sea-level rise and historical storm surges. The methodology relied on in situ data collection, observations, facility inspections, and geographic information system (GIS) analytical techniques applied to spatial data. Half of the facilities (20 of 40 surveyed) were identified as at risk of saltwater intrusion. The resulting inventory of vulnerable facilities provides a tool for decision-makers to use in determining the acceptable risk of sea-level rise when allocating future capital expenditures. 
Introduction

King County's regional wastewater system serves 1.5 million people in the greater Seattle area. It is estimated that 1 to 2 billion gallons of salt water enter the system during high tides each year through leaky gates, overflow weirs, groundwater infiltration, and local waterfront facilities and sewer connections (Figure 1). The salt water is causing premature corrosion of equipment, aggravating pipe linings, and using system capacity (King County, 2003a, 2003b, 2011). Reduced capacity can contribute to combined sewer overflows and sanitary sewer overflows. The additional flow adds to treatment, power, repair, and other costs. Given already-rising sea levels and predictions of even higher levels, WTD completed an assessment of its facilities to determine their vulnerability to future saltwater inflow.

\section{Background}

Forty facilities in the wastewater system have outfalls that extend into tidally influenced salt waters (Puget Sound and the lower Duwamish River). Most of the facilities are pump stations, regulator stations, and treatment plants. The outfalls serve as relief points during large storms, preventing excess flows from backing up in conveyance pipes and exiting to streets and buildings.

Many of these facilities have weirs, flap gates, and outfall gates that help prevent salt water from entering the system through the outfalls. The elevations of these devices are based on tidal elevations in the 1960s. However, sea level in the Seattle area rose by approximately 4.24 inches between 1950 and 2000, as measured at the National Oceanographic and Atmospheric Administration's Seattle tide gauge (NOAA 2015).

\section{Methodology}

The vulnerability assessment relied on 25 combinations of high tide elevations for current conditions, predicted sea-level rise scenarios for 2050 and 2100 (Mote et al. 2008), and four historical storm return frequencies (Zervas 2005, 2007), as shown in Table 1. The mean higher high water (MHHW) datum was used as the baseline elevation. Because the rate at which sea-level rise will occur is uncertain, the analysis focused on vulnerability at various increases in sea level, regardless of when the 


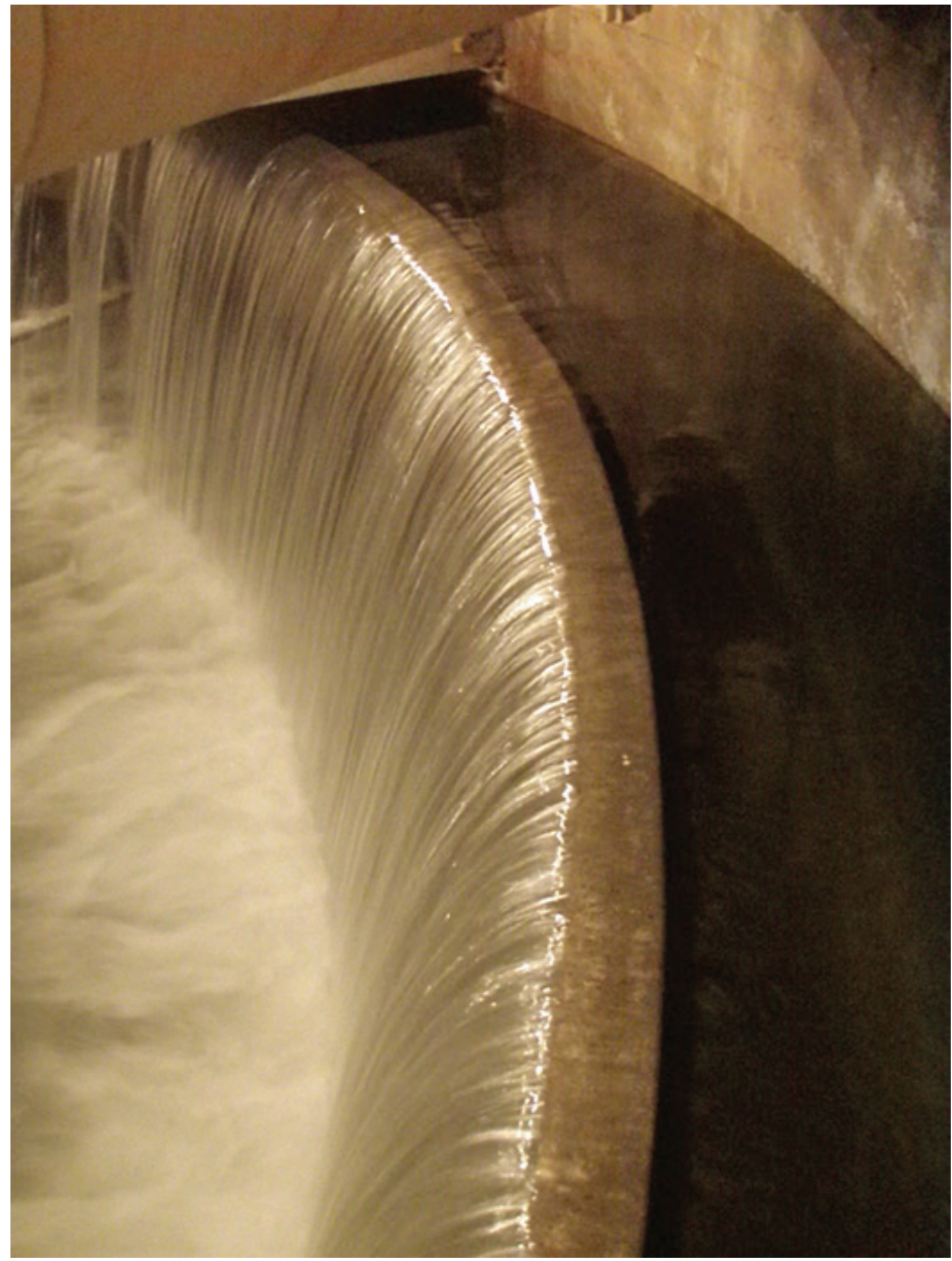

Figure 1. Salt water flowing over a weir and into a pump station. 
TABLE 1. Puget Sound High Tides under Sea-Level Rise-Storm Surge Scenarios

\begin{tabular}{lccccc}
\hline & & \multicolumn{4}{c}{ Storm Surge Plus MHHW } \\
\cline { 3 - 6 } \multicolumn{1}{c}{ Year and Sea-Level Rise } & No Storm & 1-Year Storm & $\begin{array}{c}\text { 2-Year Storm } \\
\text { (MHHW) }\end{array}$ & $\begin{array}{c}\text { 10-Year Storm } \\
\text { (1.48 feet) }\end{array}$ & $\begin{array}{c}\text { 100-Year Storm } \\
(2.27 \text { feet })\end{array}$ \\
\hline Current conditions & 9.01 & 10.49 & 11.28 & 11.80 & 12.20 \\
More likely: 2050 (6 inches) & 9.51 & 10.99 & 11.78 & 12.30 & 12.70 \\
More likely: 2100 (13 inches) & 10.09 & 11.57 & 12.36 & 12.88 & 13.28 \\
Low probability: 2050 (22 inches) & 10.84 & 12.32 & 13.11 & 13.63 & 14.03 \\
Low probability: 2100 (50 inches) & 13.18 & 14.66 & 15.45 & 15.97 & 16.37 \\
\hline
\end{tabular}

MHHW = feet above NAVD88 zero feet (9.01 feet for Seattle).

increases are predicted to occur. This approach ensures that conclusions will remain valid even as sea-level rise predictions change to incorporate new science. Facilities both with and without flap gates were considered. Although flap gates should prevent saltwater inflow, vulnerable places around the gates or improperly seated gates can allow saltwater into the system.

The methods for identifying at-risk facilities were as follows:

- Reviewed digital and hardcopy resources (as-built drawings, operation and maintenance manuals, and supervisory control and data acquisition system data). Inspected facilities to obtain their weir and gate elevations, operational settings, minimum and maximum gate openings, system connections, and capacities.

- Compared tide levels with weir elevations. Figure 2 shows the type of graph used for each sea-level rise/storm surge combination to illustrate which facilities would experience tides above their weir levels. Facilities with weir elevations lower than the highest tide level in Table 1 were considered at risk for saltwater inflow.

- Estimated saltwater inflow volumes and frequencies for at-risk facilities without flap gates.

\section{Findings}

Twenty facilities were identified as at risk for saltwater inflow (Figure 3). Most of the facilities without flap gates are at risk under the more likely sea-rise scenario, and all are at risk under the low-probability high sea-level rise scenario (Table 1). Facilities 


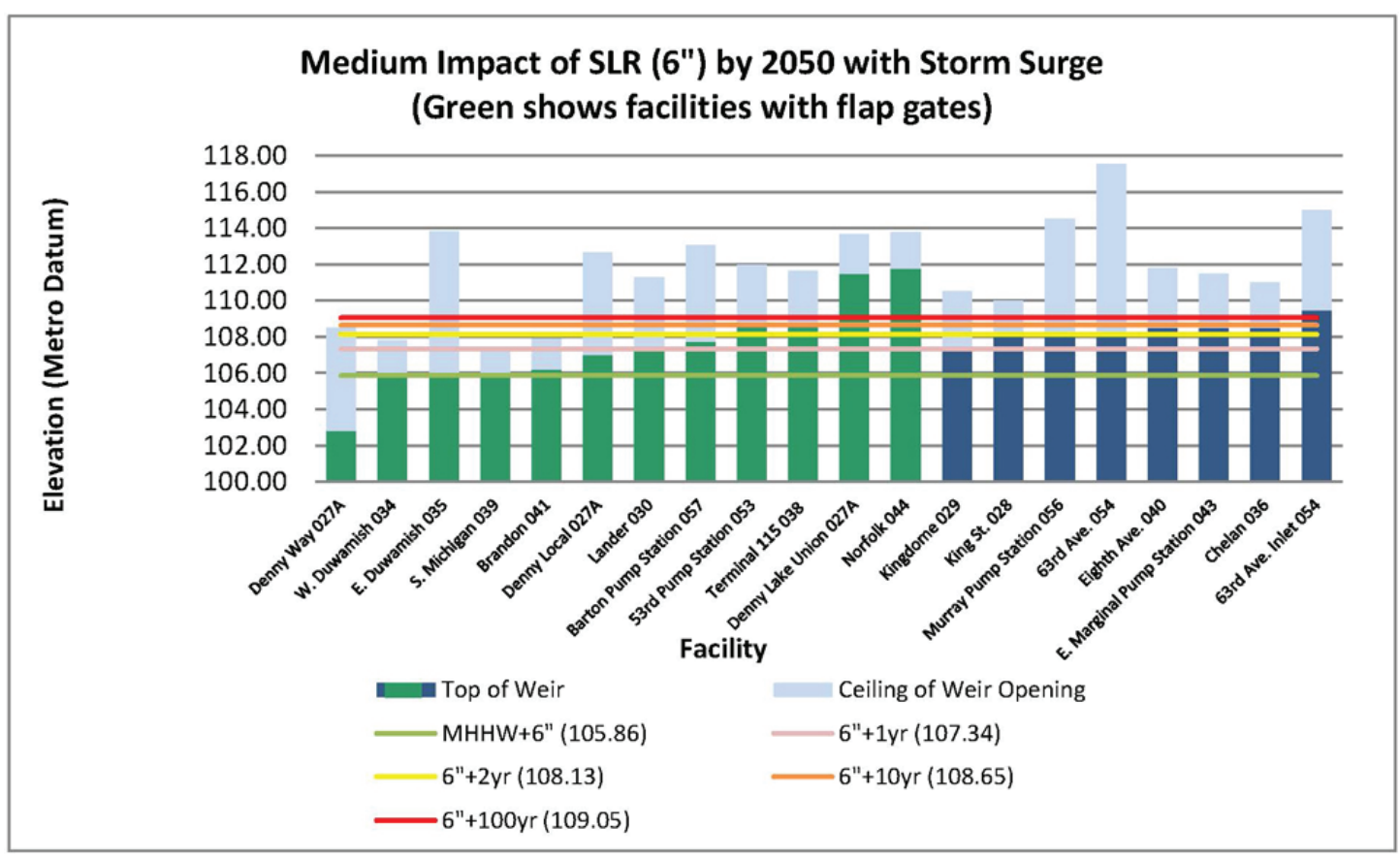

Figure 2. Tides above weir elevations with a 6-inch sea-level rise with and without storm surge.

with lower, narrower weirs would experience inflows at lower sea-level rise more frequently and at higher volumes (depending on their capacity).

A regulator station in downtown Seattle has the lowest weir of all facilities without flap gates and would experience inflow under existing high tides with surges from a storm with a two-year return frequency. The other seven facilities without flap gates would also experience inflow under existing tides but with lower-frequency, higher-intensity storms. With a sea-level rise of 6 inches plus storm surges, inflow would occur anywhere from 0 to 10 times a year, depending on the facility, increasing to over 365 times per year for all facilities with a rise of 50 inches plus storm surges. Estimated average inflow volume for each occurrence ranges from $0.01 \mathrm{mil}-$ lion to 15.05 million gallons.

\section{Next Steps}

King County is including sea-level rise in capital planning for combined sewer overflow control, asset rehabilitation, and conveyance improvements that involve any of 


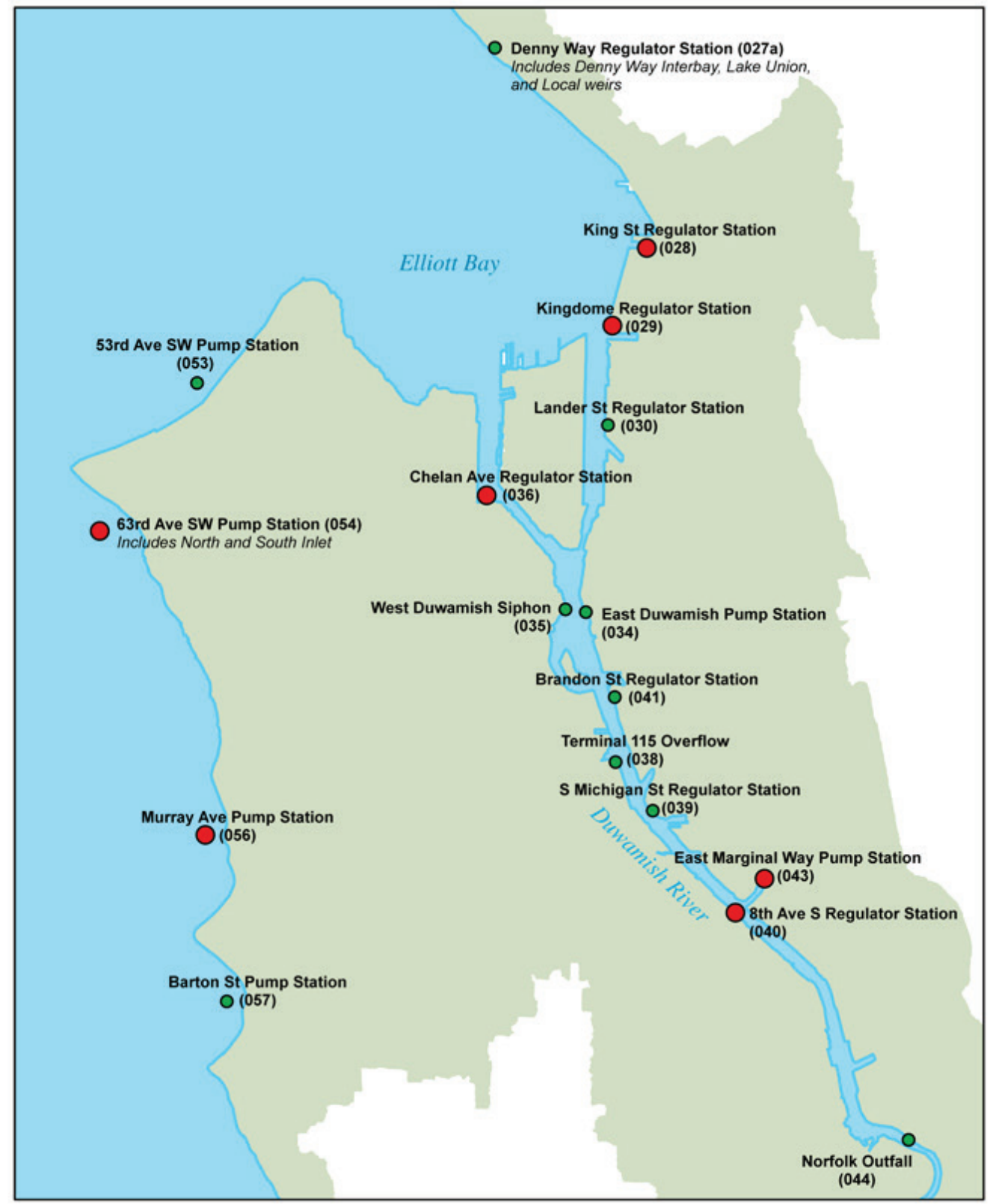

\section{Outfall Flapgates}

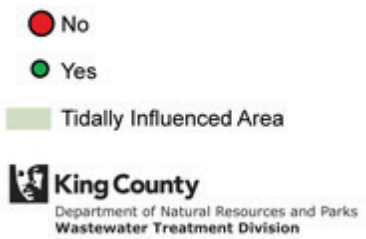

Note:

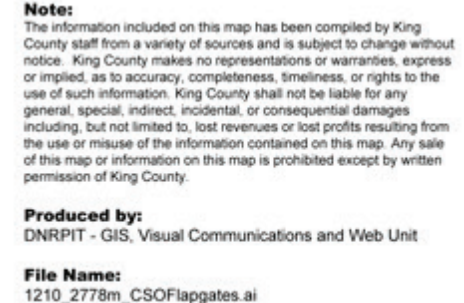

Figure 3. Locations of outfalls at risk of saltwater inflow from sea-level rise. 
the facilities being monitored for saltwater intrusion. Adaptive strategies to reduce the risk of saltwater inflow must be factored into planning over the next several decades and will include a comparison of their benefits and costs. Possible strategies include adding tide gates, raising facility elevations, and considering future sea-level rise in new facility siting.

Given the current flux of climate change research, it is likely that data used in the assessment will change as a result of updated estimates of the rate of sea-level rise and the frequency of storm events. To account for evolving conditions and predictions, King County will review scientific findings as part of system planning.

\section{References}

King County. 2003a. Saltwater Intrusion into the King County Sewer System. Seattle: King County Department of Natural Resources and Parks, Wastewater Treatment Division, Facilities Inspection Unit.

- 2003b. West Point Treatment Plant Corrosion Control Investigation. Report prepared for King County Department of Natural Resources and Parks, Wastewater Treatment Division, by Tinnea and Associates and U.S. Department of Energy, Albany Research Center. Seattle.

- 2011. Saltwater Intrusion and Infiltration into the King County Wastewater System Seattle: King County Department of Natural Resources and Parks, Wastewater Treatment Division.

Mote, Philip, Alexander Petersen, Spencer Reeder, Hugh Shipman, and Lara Whitely Binder. 2008. Sea Level Rise in the Coastal Waters of Washington State. Report prepared by the Climate Impacts Group, University of Washington, Seattle, Washington, and the Washington State Department of Ecology, Lacey, Washington.

Tide Predictions - SEATTLE 9447130 Tidal Data Daily View - NOAA Tides \& Currents. 2015. http://tidesandcurrents.noaa.gov/noaatidepredictions/NOAATidesFacade. jsp?Stationid $=9447130$.

Zervas, Chris E. 2005. "Response of Extreme Storm Tide Levels to Long-Term Sea Level Change." Oceans Proceedings of MTS/IEEE 3:2501-2506.

- 2007. Personal communication with Sascha Peterson, University of Washington Climate Impacts Group. November 9. 